\title{
Heparin-induced thrombocytopenia presenting as splenic hemorrhage following cardiac surgery: a case report
}

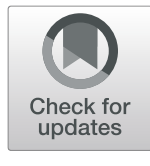

Joseph Ferry ${ }^{1 *} \mathbb{D}$, Samuel Youssef ${ }^{2}$, Pierce $\mathrm{Wu}^{2}$ and Livia Hegerova ${ }^{3}$

\begin{abstract}
Background: Heparin-induced thrombocytopenia with thrombosis (HITT) is a paradoxical prothrombotic complication of anticoagulant therapy. As many as 3\% of patients undergoing cardiac surgery develop clinical HIT presenting as thrombocytopenia with or without thrombosis within 5-10 days of heparin exposure. Thrombotic complications associated with HIT carry a mortality rate of 5-10\%.
\end{abstract}

Case presentation: We report a case of atraumatic splenic hemorrhage due to splenic vein thrombosis as the main indicator of HIT following cardiac surgery in a 62-year-old woman. She presented to the emergency department on day nine following coronary artery bypass graft surgery with acute weakness, dizziness, and malaise. Her evaluation in the emergency department found anemia and thrombocytopenia. A coagulation profile revealed a markedly elevated d-dimer. She underwent a computed tomography scan of the chest, abdomen and pelvis for suspected bleed and was found to have splenic vein thrombosis, right atrial filling defects consistent with atrial thrombus and mild to moderate hemoperitoneum. Surgical consultation was obtained due to splenic hemorrhage. Hematology was consulted on post-operative day 10, however, she unfortunately developed left sided weakness concerning for stroke. A magnetic resonance imaging scan of the brain demonstrated infarct involving distribution of the right anterior cerebral artery. A transesophageal echocardiogram demonstrated a large immobile thrombus within the right atrium with a second, mobile thrombus arising from the left tricuspid valve annulus. Due to a $4 \mathrm{Ts}$ score of 7 and markedly positive platelet factor 4 (PF4) IgG antibody a serotonin release assay was not performed given the high probability of HIT. She was cautiously treated with bivalirudin and was transitioned to warfarin anticoagulation. In the following days her platelet count recovered and 3 months later a transthoracic echocardiogram revealed solution of the intracardiac thrombi.

Conclusions: Atraumatic splenic hemorrhage is an unusual presentation of HIT that is reminiscent of the rare bilateral adrenal hemorrhage due to adrenal necrosis that also occurs in HIT. Alternative anticoagulation is the mainstay of therapy for HIT despite hemorrhage, given the underlying acquired hypercoagulability. Despite similarities of the presentation between splenic hemorrhage and bilateral adrenal hemorrhage, splenic hemorrhage is rarely described in the literature. HIT should be considered in patients presenting with thrombocytopenia following cardiac surgery.

Keywords: Bilateral adrenal hemorrhage, Heparin, Splenic infarction, Thrombocytopenia, Thrombosis

\footnotetext{
* Correspondence: joey.ferry@swedish.org

'Department of Hematology and Oncology, Swedish Medical Center, 747

Broadway 12th Fl. East Tower, Seattle, WA 98122, USA

Full list of author information is available at the end of the article
}

\section{$\triangle B M C$}

(c) The Author(s). 2021 Open Access This article is licensed under a Creative Commons Attribution 4.0 International License, which permits use, sharing, adaptation, distribution and reproduction in any medium or format, as long as you give appropriate credit to the original author(s) and the source, provide a link to the Creative Commons licence, and indicate if changes were made. The images or other third party material in this article are included in the article's Creative Commons licence, unless indicated otherwise in a credit line to the material. If material is not included in the article's Creative Commons licence and your intended use is not permitted by statutory regulation or exceeds the permitted use, you will need to obtain permission directly from the copyright holder. To view a copy of this licence, visit http://creativecommons.org/licenses/by/4.0/ The Creative Commons Public Domain Dedication waiver (http://creativecommons.org/publicdomain/zero/1.0/) applies to the data made available in this article, unless otherwise stated in a credit line to the data. 


\section{Essentials}

- HIT-associated antibodies are frequently detected after cardiac surgery

- We report a case of atraumatic splenic hemorrhage due to HIT following coronary artery bypass grafting.

- HIT should be suspected for any patient with congestive hemorrhage following venous thrombosis, thrombocytopenia, and recent heparin exposure

- Hemorrhagic splenic infarction due to splenic vein thrombosis is reminiscent of bilateral adrenal hemorrhage (BAH) due to adrenal necrosis seen in HIT

\section{Background}

Heparin-induced thrombocytopenia (HIT) is a complication of heparin therapy which occurs more commonly in postoperative than medical patients [1]. Up to $50 \%$ of patients undergoing cardiac surgery develop antibodies to platelet factor 4 (PF4) complexed to heparin, attributed to platelet activation and high heparin doses during cardiopulmonary bypass [2]. Only 1 to $3 \%$ of these patients will develop clinical HIT manifesting with thrombocytopenia with or without thrombosis [2, 3]. HIT typically presents $5-10$ days following exposure to heparin, often with platelet decline greater than $50 \%$ of baseline and is associated with life and limb-threatening thrombotic complications. HIT should be suspected in any patient who has received heparin and develops thrombocytopenia, given high mortality $(5-10 \%)$ typically a result of thrombotic complications [1].

One increasingly recognized and unusual thrombotic complication that is seen in HIT is adrenal vein thrombosis with tissue necrosis leading to bilateral adrenal hemorrhage (BAH). This congestive hemorrhage following venous thrombosis should raise high clinical suspicion for HIT. We present a case of splenic vein thrombosis post-cardiac surgery complicated hemorrhagic infarct, reminiscent of that seen in BAH, that led to the diagnosis of HIT.

\section{Case presentation}

A 62-year-old woman with a history of congestive heart failure, coronary artery disease, diabetes mellitus type 2, and recent coronary artery bypass graft (CABG) presented to the emergency department with acute weakness, dizziness, and malaise.

Past surgery history was significant for a two-vessel coronary artery bypass graft involving the left internal mammary artery to the left anterior descending artery and the left radial to obtuse marginal artery nine days prior to presentation. In the perioperative period she received three heparin boluses at $40 \mathrm{u} / \mathrm{kg}$ based on a weight of $66.7 \mathrm{~kg}$ as well as a heparin infusion dosed between $16 \mathrm{u} / \mathrm{kg} / \mathrm{hr}-26 \mathrm{u} / \mathrm{kg} / \mathrm{hr}$. for 3 days. She had no family history of hematological disorders or hypercoagulability. She was on low-dose aspirin. Her complete blood count $(\mathrm{CBC})$ was normal prior to $\mathrm{CABG}$ including platelet count of $268 \times 10 \mathrm{P}^{3} \mathrm{P} / \mu \mathrm{L}$ (normal 150-379 $\mathrm{x}$ $10 \mathrm{P}^{3} \mathrm{P} / \mu \mathrm{L}$ ) and at hospital discharge was $174 \times 10 \mathrm{P}^{3} \mathrm{P} / \mu \mathrm{L}$ with post-operative hematocrit of $36 \%$ (normal 37.5$51 \%)$.

On physical examination she was afebrile, hypotensive with systolic blood pressure in the 70s, and in rapid atrial fibrillation with heart rate $120-130 \mathrm{~s}$. She denied abdominal pain and had a benign abdominal examination. Laboratory data revealed white blood cell count $10.7 \times 10 \mathrm{P}^{9 /} \mathrm{PL}$ (normal $3.4-10.8 \times 10 \mathrm{P}^{9 /} \mathrm{PL}$ ), hematocrit $19 \%$, and platelet count of $49 \times 10 \mathrm{P}^{3} \mathrm{P} / \mu \mathrm{L}$. Complete metabolic panel and lactate were normal. Troponin was elevated at $0.21 \mathrm{ng} / \mathrm{mL}$ (normal $0.00-0.07 \mathrm{ng} / \mathrm{mL}$. Chest $\mathrm{x}$-ray was normal. A limited beside echocardiogram demonstrated no pericardial effusion. She received intravenous fluid resuscitation and transferred to the intensive care unit for further evaluation.

Upon arrival to the intensive care unit, she received 2 units of packed red blood cells with appropriate increase to hematocrit $25 \%$ post-transfusion and 1 unit of platelets with increase to $73 \times 10 \mathrm{P}^{3} \mathrm{P} / \mu \mathrm{L}$. Further laboratory evaluation was negative for hemolysis with normal lactate dehydrogenase $292 \mathrm{U} / \mathrm{L}$ (normal 119-226 U/L) and haptoglobin $98 \mathrm{mg} / \mathrm{dL}$ (normal 34-200 mg/dL). A disseminated intravascular coagulopathy (DIC) panel demonstrated d-dimer of $>40.00 \mu \mathrm{g} / \mathrm{ml}$ (normal $<=0.49 \mu \mathrm{g}$ / $\mathrm{ml}$ ), normal fibrinogen $214 \mathrm{mg} / \mathrm{dL}$ (normal 175-475 mg/ $\mathrm{dL}$ ), international normalized ratio (INR) 1.4 (normal $0.9-1.1$ ), protime (PT) $16.7 \mathrm{~s}$ (normal 12.0-14.4 s), partial thromboplastin time (PTT $37.3 \mathrm{~s}$ (normal 22.0-35.0 $\mathrm{s})$, normal thrombin time (TT), and normal red blood cell morphology.

To evaluate for bleeding, a computed tomography (CT) angiogram of the chest, abdomen, and pelvis was ordered and demonstrated filling defects suggestive of right atrial thrombus, splenic vein.

thrombosis with splenic infarct, and mild to moderate associated hemoperitoneum. She denied abdominal trauma. Surgery service was consulted and concerned about splenic hemorrhage. Hematology was consulted to evaluate the etiology of spontaneous splenic vein thrombosis with associated hemorrhagic infarction.

Unfortunately, on the day of Hematology evaluation (post-operative day 10) she developed left-sided weakness and balance changes concerning for stroke and an MRI revealed infarct involving the distribution of the right anterior cerebral artery. A transesophageal echocardiogram revealed large immobile thrombus in the 
right atrium with a second thrombus adjacent to this which was mobile and.

arising from the left tricuspid valve annulus, large thrombus in the left atrial appendage, and absence of a patent foramen ovale (Fig. 1). She was not a candidate for thrombolytic therapy due to thrombocytopenia. She was calculated to have a 4Ts score of 7. A heparin PF4 IgG antibody was.

markedly positive with 3.290 OD. Serotonin release assay was not performed due to the high probability of HIT evidenced by the markedly positive PF4 IgG and 4Ts score of 7. Together these predictive tools indicate a $72 \%$ likelihood ratio and $99 \%$ posttest probability of HIT [4]. Lower extremity ultrasound was negative for thrombosis while upper extremity ultrasound showed cephalic vein thrombosis. The patient was diagnosed with heparin-induced thrombocytopenia with thrombosis (HITT).

Given extensive thrombosis in HIT, anticoagulation was cautiously started with bivalirudin. Our organization utilizes direct thrombin inhibitor (DTI) levels to monitor and adjust bivalrudin dosing. Given the presence of hemoperitoneum prior to bivalruin dosing, bivalrudin was started at $10.01 \mathrm{mg} / \mathrm{hr}$. and titrated to $12.012 \mathrm{mg} / \mathrm{hr}$. based on DTI levels and a dose of $0.13-0.156 \mathrm{mg} / \mathrm{kg} / \mathrm{hr}$. at a weight of $77 \mathrm{~kg}$. DTI levels were maintained at goal between 60 and $90 \mathrm{~s}$ throughout therapy. She remained clinically stable from the intrabdominal hemorrhage and transitioned to warfarin anticoagulation. Platelets recovered to $108 \times 10 \mathrm{P}^{3} \mathrm{P} / \mu \mathrm{L}$ four days after starting alternative anticoagulation and greater than $150 \times 10 \mathrm{P}^{3} \mathrm{P} / \mu \mathrm{L}$ nine days after therapy for HITT initiated. The patient had repeat transthoracic echocardiogram after 3 months of warfarin anticoagulation with the resolution of intracardiac thrombi. She continues on long-term anticoagulation for atrial fibrillation.

\section{Discussion and conclusions}

Heparin-induced thrombocytopenia (HIT) is a paradoxical prothrombotic syndrome resulting from exposure to heparin-containing products [5-8]. HIT-associated antibodies are frequently detected after cardiac surgery [9]. Thrombosis in the setting of HIT is more commonly associated with the venous system, however, arterial thrombus formation is more common in patients receiving heparin for cardiovascular disease [5]. We report a case of atraumatic splenic hemorrhage due to splenic vein infarction as the main indicator of the diagnosis of HIT. The presentation is reminiscent of the rare bilateral adrenal hemorrhage due to adrenal vein thrombosis that has been reported in HIT. Given the high mortality of HIT, as high as $28 \%$ in cardiac surgery patients, awareness of these unique presentations is critical for earlier intervention [10].

HIT should be suspected in any patient who has had prior heparin exposure who presents with

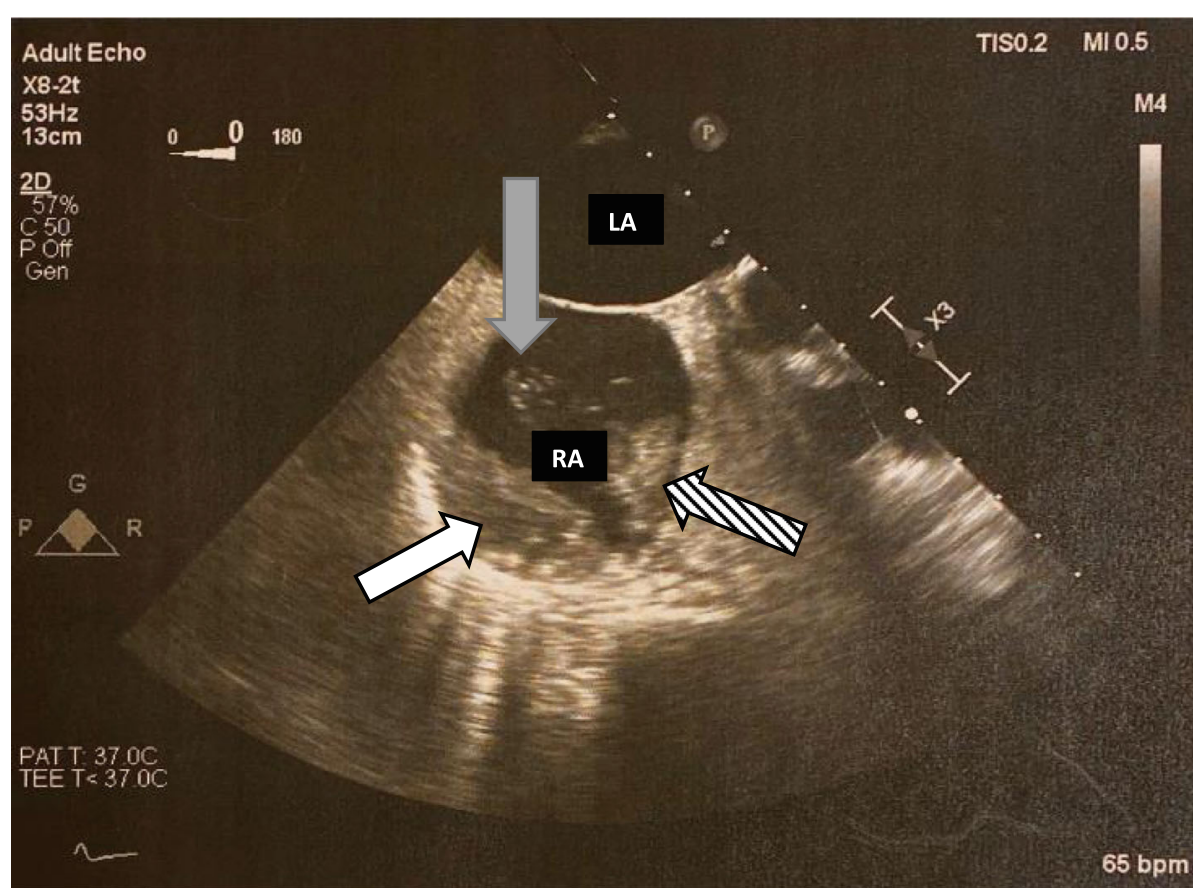

Fig. 1 Transesophageal Echocardiogram (TEE). White arrow demonstrating immobile right atrial thrombus. Striped arrow demonstrates second mobile thrombus. Grey arrow demonstrates thrombin strands originating from mobile thrombus 
thrombocytopenia, especially if the fall is greater than $50 \%$ of baseline count and whether the nadir remains within the normal range [6]. Our patient had a high $4 \mathrm{~T}$ score and HIT PF4 antibody OD of 3.2 and new splenic and atrial thrombosis, confirming a diagnosis of HITT. Anticoagulation was started with parenteral direct thrombin inhibitor and transitioned to warfarin once platelet count was within the normal limit for 2 consecutive days. Alternative anticoagulation is the mainstay of therapy for HITT even in the setting of hemorrhage, given the underlying acquired hypercoagulability.

A well-documented and increasingly well-recognized thrombotic complication of HIT is bilateral adrenal hemorrhage [7]. Clues to this rare complication include the development of abdominal pain, diarrhea, and fever which often lead to imaging of the abdomen and revelation of injury to the adrenal glands and is confirmed by corticotropin-stimulation test $[7,11]$. The risk of $\mathrm{BAH}$ in a case study of HIT by Warkentin et. al was $1.6 \%$ [12]. Strong arterial blood supply with a single central vein makes the.

adrenal glands susceptible to congestive hemorrhage following venous thrombosis [13]. We hypothesize that the spleen is at similar risk given it too has a rich arterial supply and single splenic vein.

A literature review reveals few reported cases of splenic vein thrombosis with hemorrhagic infarction as a clinical sequela of HIT. Earlier reports discussed spontaneous splenic ruptures occurring on heparin anticoagulants, however did not report on HIT antibody testing [14-17]. One case report had a very similar presentation of splenic hematoma after cardiac surgery, with splenectomy pathology showing multiple fibrin thrombi in the spleen [9]. This pathology confirms our hypothesis of microthrombi leading to subsequent hemorrhagic conversion in the spleen, as occurs in BAH.

Early imaging to identify these unusual intraabdominal thrombotic complications of HIT is encouraged [18]. A case report by Lammering et al. discusses a case of splenic rupture secondary to splenic vein thrombosis resulting from HIT, while the discussion focuses on the utility of multidetector-.

row computed tomography in the rapid and accurate diagnosis of HIT related thromboembolic complication. Lammering et al. describe the case in the setting of nonspecific abdominal pain which differed from our patient without abdominal pain [19].

Treatment of HIT involves alternative non-heparin anticoagulation in accordance with published guidelines including those by the American College of Chest Physicians and the updated American Society of Hematology Guidelines for Management of Venous Thromboembolism: Heparin-Induced Thrombocytopenia [1, 20]. Despite hemorrhagic complications such as $\mathrm{BAH}$, or as in our patient intraabdominal hemorrhage due to splenic infarction, treatment is careful anticoagulation given the underlying etiology for hemorrhage is hypercoagulability. Multiple cases reports on BAH advocate for prompt initiation of appropriate anticoagulation to ensure a successful outcome [12, 21]. We advocate for a similar approach to congestive splenic hemorrhage following splenic vein thrombosis as a consequence of HIT.

This case emphasizes that the diagnosis of HIT should be considered for patients with unusual intra-abdominal thrombosis or hemorrhage, especially within the expected time course following heparin exposure.

Congestive hemorrhage following venous thrombosis, with recent heparin exposure and declining platelet count, should raise clinical suspicion of HIT. The diagnosis of HIT-induced splenic vein thrombosis and subsequent hemorrhagic infarct mimics the rare bilateral adrenal hemorrhage due to adrenal vein thrombosis seen in HIT. Multidetector-row computed tomography should be considered for the evaluation of thromboembolic sequelae in patients with unexplained anemia or abdominal pain with suspicion of HITT to exclude adrenal or splenic involvement. Alternative anticoagulation remains the mainstay of therapy.

\section{Abbreviations}

BAH: bilateral adrenal hemorrhage; CABG: coronary artery bypass graft; CBC: complete blood count; CT: computed tomography; DIC: disseminated intravascular coagulopathy; HITT: heparin induced thrombocytopenia with thrombosis; HIT: heparin induced thrombocytopenia; PT: protime; PTT: partial thromboplastin time; TT: thrombin time

\section{Acknowledgments}

None

\section{Authors' contributions}

JF wrote the manuscript. JF, SY, PW LH treated the patient. LH revised and edited the manuscript. All authors have read and approved the manuscript

\section{Funding}

None.

Availability of data and materials

No datasets were developed or analyzed for this case report.

Ethics approval and consent to participate

In the United States, a case report does not require ethics approval.

Consent for publication

Written informed consent was obtained from the patient for publication of this case report and any accompanying images. A copy of the written consent is available for review by the Editor-in-Chief of this journal.

\section{Competing interests}

The authors declare that they have no competing interests.

\section{Author details}

1Department of Hematology and Oncology, Swedish Medical Center, 747 Broadway 12th Fl. East Tower, Seattle, WA 98122, USA. ${ }^{2}$ Swedish Heart and Vascular - Cardiac Surgery, Seattle, WA, USA. ${ }^{3}$ Swedish Center for Blood Disorders and Stem Cell Transplantation, Seattle, WA, USA. 
Received: 10 June 2020 Accepted: 11 January 2021

Published online: 19 January 2021

\section{References}

1. Linkins LA, Dans AL, Moores LK, Bona R, Davidson BL, Schulman S, et al. Treatment and prevention of heparin-induced thrombocytopenia: antithrombotic therapy and prevention of thrombosis, 9th ed: American College of Chest Physicians Evidence-Based Clinical Practice Guidelines. Chest. 2012;141(2 Suppl):e495S-530S.

2. Lillo-Le Louet A, Boutouyrie P, Alhenc-Gelas M, Le Beller C, Gautier I, Aiach $M$, et al. Diagnostic score for heparin-induced thrombocytopenia after cardiopulmonary bypass. J Thromb Haemost. 2004;2(11):1882-8.

3. Salter BS, Weiner MM, Trinh MA, Heller J, Evans AS, Adams DH, et al. Heparin-induced thrombocytopenia: a comprehensive clinical review. J Am Coll Cardiol. 2016;67(21):2519-32.

4. Cuker A. Clinical and laboratory diagnosis of heparin-induced thrombocytopenia: an integrated approach. Semin Thromb Hemost. 2014; 40(1):106-14.

5. Ahmed I, Majeed A, Powell R. Heparin induced thrombocytopenia: diagnosis and management update. Postgrad Med J. 2007;83(983):575-82.

6. Baglin TP. Heparin induced thrombocytopenia thrombosis (HIT/T) syndrome: diagnosis and treatment. J Clin Pathol. 2001;54(4):272-4.

7. Bakaeen FG, Walkes JC, Reardon MJ. Heparin-induced thrombocytopenia associated with bilateral adrenal hemorrhage after coronary artery bypass surgery. Ann Thorac Surg. 2005;79(4):1388-90.

8. Chow WW, Abnousi F, Huddleston Jl, Lin LH. Heparin-induced thrombocytopenia after total knee arthroplasty, with subsequent adrenal hemorrhage. J Arthroplasty. 2012;27(7):1413 e15-8.

9. Mitchell C, Riley CA, Vahid B. Unusual complication of heparin-induced thrombocytopenia after mitral valve surgery: spontaneous rupture of spleen. Ann Thorac Surg. 2007;83(3):1172-4

10. Warkentin TE, Greinacher A. Heparin-induced thrombocytopenia and cardiac surgery. Ann Thorac Surg. 2003;76(6):2121-31.

11. Rosenberger LH, Smith PW, Sawyer RG, Hanks JB, Adams RB, Hedrick TL. Bilateral adrenal hemorrhage: the unrecognized cause of hemodynamic collapse associated with heparin-induced thrombocytopenia. Crit Care Med. 2011;39(4):833-8.

12. Warkentin TE, Kelton JG. A 14-year study of heparin-induced thrombocytopenia. Am J Med. 1996;101(5):502-7.

13. Saleem N, Khan M, Parveen S, Balavenkatraman A. Bilateral adrenal haemorrhage: a cause of haemodynamic collapse in heparin-induced thrombocytopaenia. Case Rep. 2016;2016:bcr2016214679.

14. Burg MD, Dallara JJ. Rupture of a previously normal spleen in association with enoxaparin: an unusual cause of shock. J Emerg Med 2001;20(4):349-52.

15. Ghobrial MW, Karim M, Mannam S. Spontaneous splenic rupture following the administration of intravenous heparin: case report and retrospective case review. Am J Hematol. 2002;71(4):314-7.

16. Pilkey RM, Lawrence MD, Wolfsohn AL, Walley VM. Splenic rupture resulting from acute pancreatitis after cardiac surgery with intra-aortic balloon pumping: case report. Can J Surg. 1994;37(5):428-9.

17. Warkentin TE, Safyan EL, Linkins LA. Heparin-induced thrombocytopenia presenting as bilateral adrenal hemorrhages. N Engl J Med. 2015;372(5): 492-4.

18. Weiss SJ, Smith T, Laurin E, Wisner DH. Spontaneous splenic rupture due to subcutaneous heparin therapy. J Emerg Med. 2000;18(4):421-6.

19. Lammering JC, Wang DS, Shin LK. Heparin-induced thrombocytopenia (HIT) causing portosplenic, superior mesenteric, and splenic vein thrombosis resulting in splenic rupture and pulmonary emboli formation. Clin Imaging. 2012;36(6):865-8

20. Cuker A, Arepally GM, Chong BH, Cines DB, Greinacher A, Gruel Y, et al. American Society of Hematology 2018 guidelines for management of venous thromboembolism: heparin-induced thrombocytopenia. Blood Adv. 2018;2(22):3360-92.

21. Kurtz LE, Yang S. Bilateral adrenal hemorrhage associated with heparin induced thrombocytopenia. Am J Hematol. 2007;82(6):493-4.

\section{Publisher's Note}

Springer Nature remains neutral with regard to jurisdictional claims in published maps and institutional affiliations.

Ready to submit your research? Choose BMC and benefit from:

- fast, convenient online submission

- thorough peer review by experienced researchers in your field

- rapid publication on acceptance

- support for research data, including large and complex data types

- gold Open Access which fosters wider collaboration and increased citations

- maximum visibility for your research: over $100 \mathrm{M}$ website views per year

At $\mathrm{BMC}$, research is always in progress.

Learn more biomedcentral.com/submissions 